\title{
SPECT-CT imaging with [99mTC]PSMA-T4 in patients with recurrent prostate cancer
}

\author{
Sonya Sergieva1 ${ }^{1}$ Radoslav Mangaldgiev², Milena Dimcheva', Kamen Nedev³, Zahary Zahariev4, Bozhil Robev ${ }^{5}$ \\ ${ }^{1}$ Department of Nuclear Medicine, Sofia Cancer Centre, Sofia, Bulgaria \\ 2Department of Medical Oncology, Sofia Cancer Centre, Sofia, Bulgaria \\ ${ }^{3}$ Department of Radiotherapy, Acibadem City Clinic, Sofia, Bulgaria \\ ${ }^{4}$ Department of Radiotherapy, UniHospiatal, Panagyurishte, Bulgaria \\ ${ }^{5}$ Department of Medical Oncology, UH "St Ivan Rilsky", Sofia, Bulgaria
}

[Received 12 II 2021; Accepted 19 VII 2021]

\begin{abstract}
Background: Prostate-specific membrane antigen (PSMA) is a cell surface glycoprotein with a large extracellular domain with overexpression of the prostatic tumour cells. Several small molecules of PSMA ligands of inhibitors binding to the active site of PSMA were developed. [99mTc]TC-PSMA-T4 is a new radiopharmaceutical (Polatom) for imaging loco-regional metastases and/or local relapse in patients with prostate cancer.
\end{abstract}

The purpose of this work was to evaluate the clinical application of SPECT-CT imaging with [99mTc]Tc-PSMA-T4 in patients with recurrent prostate cancer.

Material and methods: Thirty-six patients with prostate cancer, aged 60-80 years with biochemical relapse of PSA (ranged from 0.1 to $73 \mathrm{ng} / \mathrm{mL}$ ) were included. Three patients were studied after tru-cut biopsy, hormonal and cytoreductive radiotherapy and 33 patients out of 36 - after radical treatment (total prostatectomy or definitive radiotherapy of the tumour). All of them underwent whole-body imaging examinations with subsequent target SPECT-CT studies of the pelvis, abdomen and/or chest, 1-3 hrs post i.v. administration of [99mTc]TC-PSMA-T4. The average activity dose was $6.3 \mathrm{MBq} / \mathrm{kg}$ in a man of $70 \mathrm{~kg}$. A Dual-head SPECT-CT gamma camera with a low dose CT scan (Symbia T2, Siemens) was used. The images were interpreted based on all other clinical and radiological data. Follow-up could be conducted in 11/36 patients during that period.

Results: Normal biodistribution of the radiopharmaceutical with high activity background was observed in the liver, spleen, kidneys, lacrimal and salivary glands, bowels and urinary bladder. Positive imaging for local relapse in the prostate bad was imaged in 21 patients, lymph node metastases — in 16 cases, bone lesions — in 10 cases, pulmonary metastases - in 2 cases, hepatic lesions were visualised in one of them and in another - adrenal suprarenal metastasis with intensive tracer uptake significant for overexpression of PSMA. There was a suspicion for local recurrences in 4 patients with negative MRT studies who were followed up. In 3 cases, previously treated bone metastases were partially negative without tracer uptake, only some progressive bone lesions were positive. Five patients were with negative results. Sensitivity was $84.37 \%$ (27/32), specificity $100 \%(4 / 4)$ and accuracy $-86.11 \%(31 / 36)$.

Conclusions: In conclusion SPECT-CT imaging with [99mTc]Tc-PSMA-T4 could be applied in patients with prostate cancer for the diagnosis of recurrent disease to determine personalized treatment for each patient. Specific uptake of this tracer, depicted by SPECT-CT images has clinical importance of identifying and assessing PSMA expression before consideration of Radio Ligand Therapy (RLT) with [ ${ }^{177} \mathrm{Lu}$ ]Lu-PSMA. SPECT-CT imaging with [ ${ }^{99 \mathrm{~m} T C] P S M A}$ is promising and reliable nuclear medicine approach to monitoring therapeutic effect after treatment and for restaging of the disease.

KEY words: recurrent prostate cancer; PSMA; [99mTc]TC-PSMA-T4; SPECT-CT

Nucl Med Rev 2021; 24, 2: 70-81

Correspondence to: Sonya Sergieva

Department of Nuclear Medicine, Sofia Cancer Centre, Blvd.

"Andrey Saharov"22, Sofia - 1784, Bulgaria

e-mail: sergieva.sonya@yahoo.com

This article is available in open access under Creative Common Attribution-Non-Commercial-No Derivatives 4.0 International (CC BY-NC-ND 4.0) license, allowing to download articles and share them with others as long as they credit the authors and the publisher, but without permission to change them in any way or use them commercially. 


\section{Introduction}

Prostate cancer is the most common malignancy in men in Europe. According to forecast statistics for 2018, the number diagnosed with this disease is 450,000 men or $20 \%$ of all cases of malignancies in them [1]. This disease is socially significant both in Bulgaria and in the countries of the European Union. The incidence in 2018 (standardized indicator per 100,000 men) varies from 80.2 in Romania to 265.2 in Ireland. In Bulgaria, the incidence is 136.4, 14\% lower than the European Union average, but with a tendency to increase. Mortality in 2018 varies from 22.7 in Italy to 73.9 in Estonia. In Bulgaria, the mortality rate is 40.1 and is $7 \%$ higher than the average for the European Union, with a tendency to increase, and the survival rate is the lowest among the European - 68\% $[1,2]$. Interpretation of these factual data points out that modern diagnostic and therapeutic methods have not yet shown their impact on epidemiological indicators in Bulgaria as well as in some other European countries. The reasons for this are complex and diverse for different countries.

One of the important clinical problems is the early detection and visualization of recurrences after prostatectomy, radiotherapy or other definitive local treatment, with PSA values above $0.2 \mathrm{ng} / \mathrm{mL}$. Contrast-enhanced magnetic resonance imaging (MRI) and computed tomography (CT) scans are most commonly used, but they are not always of sufficient sensitivity and specificity, especially at low tumour marker values [3, 4].

With the introduction of molecular high sensitive imaging after administration of radiolabelled prostate-specific membrane antigen (PSMA), it has become possible to obtain early functional information for disease development and recurrence detection, which is more accurate than that of CT or MRI in many cases $[5,6]$.

Prostate-specific membrane antigen (PSMA) is a cell surface glycoprotein with a large extracellular domain with overexpression of the prostatic tumour cells. This membrane antigen is known as glutamate carboxypeptidase II (GCP II), a membrane-bound binuclear zinc metallopeptidase, which is available in low concentrations in normal kidney, intestinal tissue and salivary glands $[7,8]$. PSMA overexpression is observed also in endothelial cells of tumour neovasculature of non-prostatic solid tumours and benign lesions: colon, gastric, breast, thyroid, ovary; Paget Disease, probably stimulated by secreted angiogenic factors. Upon ligand binding, PSMA is internalized via endocytosis in the tumour cell $[7,8]$.

In recent years in the clinical practice, a new concept was introduced for specific diagnosis and targeted effective radionuclide treatment of metastatic prostate cancer (PC) after administration of a target PSMA molecule, labelled with various radionuclides, on the principles of theranostics [9, 10].

The degree of intensity of PSMA overexpression epithelial cells in PC is proportional to the degree of malignant cell dedifferentiation and metastatic spread [7, 8]. The field of radiopharmacy and radiochemistry over the last decade is focused on the development of small ligand molecules or binding inhibitors with the active PSMA core, which are characterized by high specificity, good permeability in solid tumours, optimal pharmacokinetics in normal tissues, easily labelled and synthesized, no host-immune response in the recipient $[7,8]$.
Such PSMA ligands can be labelled with different radionuclides, respectively with ${ }^{68} \mathrm{Ga},{ }^{18} \mathrm{~F},{ }^{99 m} \mathrm{Tc},{ }^{123} / 124$ l (emitting positron or gamma emission) for diagnostic purposes or with ${ }^{177} \mathrm{Lu},{ }^{131} \mathrm{I},{ }^{90} \mathrm{Y},{ }^{225} \mathrm{Ac}$ (emitting beta or alpha emissions) to conduct target radioligand therapy. The most used diagnostic radiopharmaceutical is the ${ }^{68} \mathrm{Ga}$ PSMA-11 inhibitor $[6,8,10]$.

After intravenous application of gamma-emitting radiopharmaceutical [ $\left.{ }^{99 m} \mathrm{Tc}\right] \mathrm{PSMA}$ or positron-emitting [ $\left.{ }^{68} \mathrm{Ga}\right] \mathrm{PSMA}$, positive scans were significant for the presence of PSMA overexpression, this information is important for the assessment of malignant lesions and disease extension [5, 6].

Several small molecules of PSMA ligands or inhibitors were developed. One such small ligand binding to the active site of PSMA, namely PSMA-T4 (Glu-CO-Lys-L-Trp-4-Amc-HYNIC) and the kit formulation for its radiolabelling with technetium-99m resulting in the ${ }^{99 m \mathrm{~m} T}$ ] Tc-PSMA-T4radiopharmaceutical were developed at Radioisotope Centre Polatom, National Centre for Nuclear Research in Otwock, Poland.

The purpose of this study was to evaluate the clinical role of [99mTC]TC-PSMA-T4 for imaging of local relapse and/or loco-regional and distant metastases in patients with recurrent prostate cancer and biochemical disease progression.

\section{Material and methods}

\section{Patients}

This was a prospective study conducted in the period January 2019 - January 2020 after preliminary approval of this scientific project on the Local Ethics Committee. A cohort of 36 patients, aged 60-80 years/average of 69.44 years/ with prostate cancer was examined after obtaining written informed consent. Three patients underwent tru-cut biopsy, hormonal and cytoreductive radiotherapy; 33 patients out of 36 received radical treatment of primary cancer (total prostatectomy or definitive radiotherapy of the tumour). There was laboratory data on biochemical disease progression — serum value elevation of the tumour marker PSA and its doubling within 6 months. The average serum PSA level before SPECT-CT imaging was $6.73 \mathrm{ng} / \mathrm{mL}$ (ranged from 0.1 to $73 \mathrm{ng} / \mathrm{mL}$ ) (Tab. 1).

All of the patients underwent whole-body imaging examinations with target SPECT-CT studies 1-3 hrs post intravenous administration of ${ }^{[99 \mathrm{~m} T c] T C-P S M A-T 4 .}$

\section{Radiolabelling}

PSMA-T4 (Glu-CO-Lys-L-Trp-4-Amc-HYNIC, 23 mcg) in the form of a dry kit for radiolabelling with technetium-99m has been obtained from National Centre for Nuclear Research (Polatom, Poland) and was radiolabelled with technetium-99m according to the procedure: to the kit vial, 1 to $2.5 \mathrm{~mL}$ of sodium pertechnetate solution (eluate from the ${ }^{99} \mathrm{Mo} /{ }^{99 m} \mathrm{Tc}$ generator) with radioactivity in the range from 370 to $1500 \mathrm{MBq}$ was added. The content of the vial was gently mixed for 30 seconds to allow complete dissolution, then heated in the boiling water bath for $15 \mathrm{~min}$ and afterwards cooled down at room temperature for $10 \mathrm{~min}$. Radiolabelling yield was more than 95\% as assessed by instant thin-layer chromatography (ITLC).

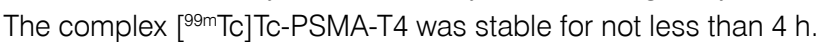

The average activity dose injected intravenously was $6.3 \mathrm{MBq} / \mathrm{kg}$ in a man of $70 \mathrm{~kg}$. 
Table 1. Clinical and pathological characteristics of the 36 patients with biochemical recurrence of prostate cancer

\begin{tabular}{|c|c|c|c|c|}
\hline Pt No/Age & TNM Stage & Gleason Score & PSA at SPECT-CT Image & Primary Therapy \\
\hline $1 / 67$ years & pT3bpN1M0 & $7(4+3)$ & $0.271 \mathrm{ng} / \mathrm{mL}$ & RP, RT, ADT \\
\hline $2 / 73$ years & T3N0M0 & $7(4+3)$ & $12 \mathrm{ng} / \mathrm{mL}$ & RT, ADT \\
\hline $4 / 68$ years & pT2pNOMO & $7(4+3)$ & $0.30 \mathrm{ng} / \mathrm{mL}$ & $\mathrm{RP}$ \\
\hline $5 / 67$ years & T3N1M0 & $9(5+4)$ & $9.68 \mathrm{ng} / \mathrm{mL}$ & RT,ADT \\
\hline $6 / 64$ years & T3bN1M0 & $9(5+4)$ & $2.15 \mathrm{ng} / \mathrm{mL}$ & $\begin{array}{l}\text { Cytoreductive RT, ADT, } \\
\text { Chemotherapy }\end{array}$ \\
\hline $7 / 63$ years & pT2pNOMO & $7(3+4)$ & $0.12 \mathrm{ng} / \mathrm{mL}$ & $\mathrm{RP}$ \\
\hline $8 / 65$ years & pT3pNOMO & $6(3+3)$ & $0.36 \mathrm{ng} / \mathrm{mL}$ & $\mathrm{RP}$ \\
\hline $9 / 70$ years & pT2pNOMO & $7(3+4)$ & $0.24 \mathrm{ng} / \mathrm{mL}$ & $\mathrm{RP}, \mathrm{RT}$ \\
\hline $10 / 64$ years & pT2cpN0M1 & $7(4+3)$ & $0.82 \mathrm{ng} / \mathrm{mL}$ & RP, ADT \\
\hline $11 / 70$ years & pT2pNOMO & $7(4+3)$ & $0.69 \mathrm{ng} / \mathrm{mL}$ & RP,ADT \\
\hline $13 / 60$ years & pT2pNOMO & $5(3+2)$ & $0.50 \mathrm{ng} / \mathrm{mL}$ & $\mathrm{RP}$ \\
\hline $14 / 64$ years & T3aNOMO & $7(4+3)$ & $0.16 \mathrm{ng} / \mathrm{mL}$ & RP, ADT \\
\hline 15/74years & pT3bpN1M0 & $9(5+4)$ & $0.35 \mathrm{ng} / \mathrm{mL}$ & RP, RT, ADT, Chemotherapy \\
\hline 16/75years & pT2cpNOMO & $7(4+3)$ & $0.57 \mathrm{ng} / \mathrm{mL}$ & RP, RT, ADT \\
\hline 17/75years & pT2cpNOMO & $7(4+3)$ & $0.36 \mathrm{ng} / \mathrm{mL}$ & $\mathrm{RP}$ \\
\hline 18/70years & T3bNOM1 & $7(3+4)$ & $58 \mathrm{ng} / \mathrm{mL}$ & $\mathrm{RT}, \mathrm{ADT}$ \\
\hline 19/62years & T3bN1M1 & $8(4+4)$ & $0.66 \mathrm{ng} / \mathrm{mL}$ & Cytoreductive RT, ADP \\
\hline 20/68years & T2NxM1 & $7(4+3)$ & $0.41 \mathrm{ng} / \mathrm{mL}$ & $\mathrm{RT}, \mathrm{ADT}$ \\
\hline 21/63years & T3aNOMO & $7(4+3)$ & $1.78 \mathrm{ng} / \mathrm{mL}$ & $\mathrm{RT}, \mathrm{ADT}$ \\
\hline 22/77years & pT2pNOMO & $7(3+4)$ & $1.5 \mathrm{ng} / \mathrm{mL}$ & RP, ADT \\
\hline 23/69years & T2NxM0 & $7(4+3)$ & $7.3 \mathrm{ng} / \mathrm{mL}$ & RT, ADT \\
\hline 26/77years & T3aNOMO & $7(3+4)$ & $0.8 \mathrm{ng} / \mathrm{mL}$ & RT \\
\hline 27/66years & T2NOMO & $8(4+4)$ & $1.88 \mathrm{ng} / \mathrm{mL}$ & $\mathrm{RT}$ \\
\hline 28/69years & рT2pNOMO & $7(4+3)$ & $0.25 \mathrm{ng} / \mathrm{mL}$ & $\mathrm{RP}, \mathrm{RT}$ \\
\hline 29/60years & рT2pNOMO & $5(3+2)$ & $0.77 \mathrm{ng} / \mathrm{mL}$ & RP, ADT \\
\hline 30/78years & $\mathrm{T} 1 \mathrm{cN} 1 \mathrm{M} 1$ & $8(4+4)$ & $27 \mathrm{ng} / \mathrm{mL}$ & RT, ADP \\
\hline 31/69years & pT2NOMO & $5(3+2)$ & $1.6 \mathrm{ng} / \mathrm{mL}$ & RP, ADP \\
\hline 32/70years & pT2NOMO & $7(4+3)$ & $0.23 \mathrm{ng} / \mathrm{mL}$ & $\mathrm{RP}, \mathrm{RT}$ \\
\hline 33/73years & T4N1M0 & $9(4+5)$ & $0.30 \mathrm{ng} / \mathrm{mL}$ & Cytoreductive RT, ADP \\
\hline 34/80years & T2NOMO & $7(4+3)$ & $5.90 \mathrm{ng} / \mathrm{mL}$ & $\mathrm{RT}, \mathrm{ADP}$ \\
\hline 35/70years & pT3bpNOMO & $8(4+4)$ & $1.72 \mathrm{ng} / \mathrm{mL}$ & RP, ADP \\
\hline 36/71years & pT2cpNOMO & $8(5+3)$ & $0.47 \mathrm{ng} / \mathrm{mL}$ & RT, ADP \\
\hline
\end{tabular}

$\mathrm{RP}$ - radical prostatectomy; RT — radiotherapy; ADT — androgen deprivation therapy

\section{Imaging protocol}

Whole-body imaging examinations with subsequent target SPECT-CT studies of the pelvis, abdomen and/or chest and were carried out 1-3 hrs. after tracer application. SPECT-CT gamma camera Symbia T2, Siemens, was used for topographic localization and morphological substratum of "hot" abnormal foci. Dual-headSPECT acquisition included 64 projections, 25 s/projection, matrix $256 \times 256$. A low dose CT scan was performed in the helical mode. Acquisition parameters included settings at $130 \mathrm{kV}, 30 \mathrm{~mA} ; 3-5 \mathrm{~mm}$ slice thickness.
SPECT-CT images were analysed considering any focal abnormal uptake of ${ }^{99 \mathrm{~m} T \mathrm{~T}]}$ ] Tc-PSMA-T4 above the surrounding background level, not associated with physiological biodistribution, suggestive of malignancy. The diagnostic differentiation between malignant and inflammatory lymph nodes is based not only on the intensity of tracer accumulation but also on the morphological structure of the nodule and the anatomical localization, especially if the accumulation is bilaterally symmetrical in the inguinal, hilar or axillary lymph nodes. The obtained SPECT-CT results were compared with the data from the 
previously conducted diagnostic imaging studies - computed tomography, magnetic resonance tomography, bone scintigraphy. The images were interpreted based on all other clinical and radiological data.

Follow-up SPECT-CT studies with[99mTc]TC-PSMA-T4 were performed in 11/36 patients to monitor and evaluate the results of baseline scans and conducted treatment.

\section{Results}

Normal biodistribution of the radiopharmaceutical with high activity background was observed in the liver, spleen, kidneys, lacrimal and salivary glands, oral and nasal mucosa, bowels and urinary bladder (Fig. 1).

Positive imaging for local relapse in the prostate bad was imaged in 21 patients, pelvic and extra pelvic lymph node metastases — in 16 cases, bone lesions — in 10 cases, visceral lesions — in 3 cases: pulmonary metastases - in 2 cases, hepatic and adrenal suprarenal metastases - in one of them (Fig. 2-7). The smallest visualized positive lymph node was axial in size $9.2 \mathrm{~mm}$ (Fig. 2). All abnormal "hot" spots were scanned with intensive tracer uptake significant for PSMA overexpression.
There was a suspicion of local recurrence in the prostate bed in 4 patients with negative MRT imaging who were followed up after 6 months. The presence of the pathological findings was confirmed by the performed control studies with [ ${ }^{99 \mathrm{~m} T \mathrm{~T}]}$ TC-PSMA-T4, as they were also positive by the computed tomography or magnetic resonance imaging carried out in parallel.

In 4 patients negative results were obtained for local recurrence of the prostate, no lymphogenic spread or hematogenous dissemination of the disease was observed. In these cases, the level of the tumour marker PSA decreased in the control studies, for these

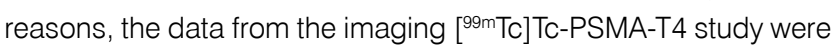
interpreted as truly negative (Fig. 4).

In 3 cases with multiple bone metastases, treated palliatively with radiotherapy and osteomodulators, tracer uptake was found only in some progressive bone lesions. There was a lack of activity in most osteosclerotic foci, probably due to a suppressed osteoblastic process after treatment (Figure 7). In one of these patients,

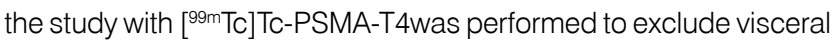
and lymphogenic dissemination of the disease to plan treatment with Xofigo infusion (Fig. 8).

Targeted radiotherapy was performed in seven patients with a positive result for the development of local recurrence in the

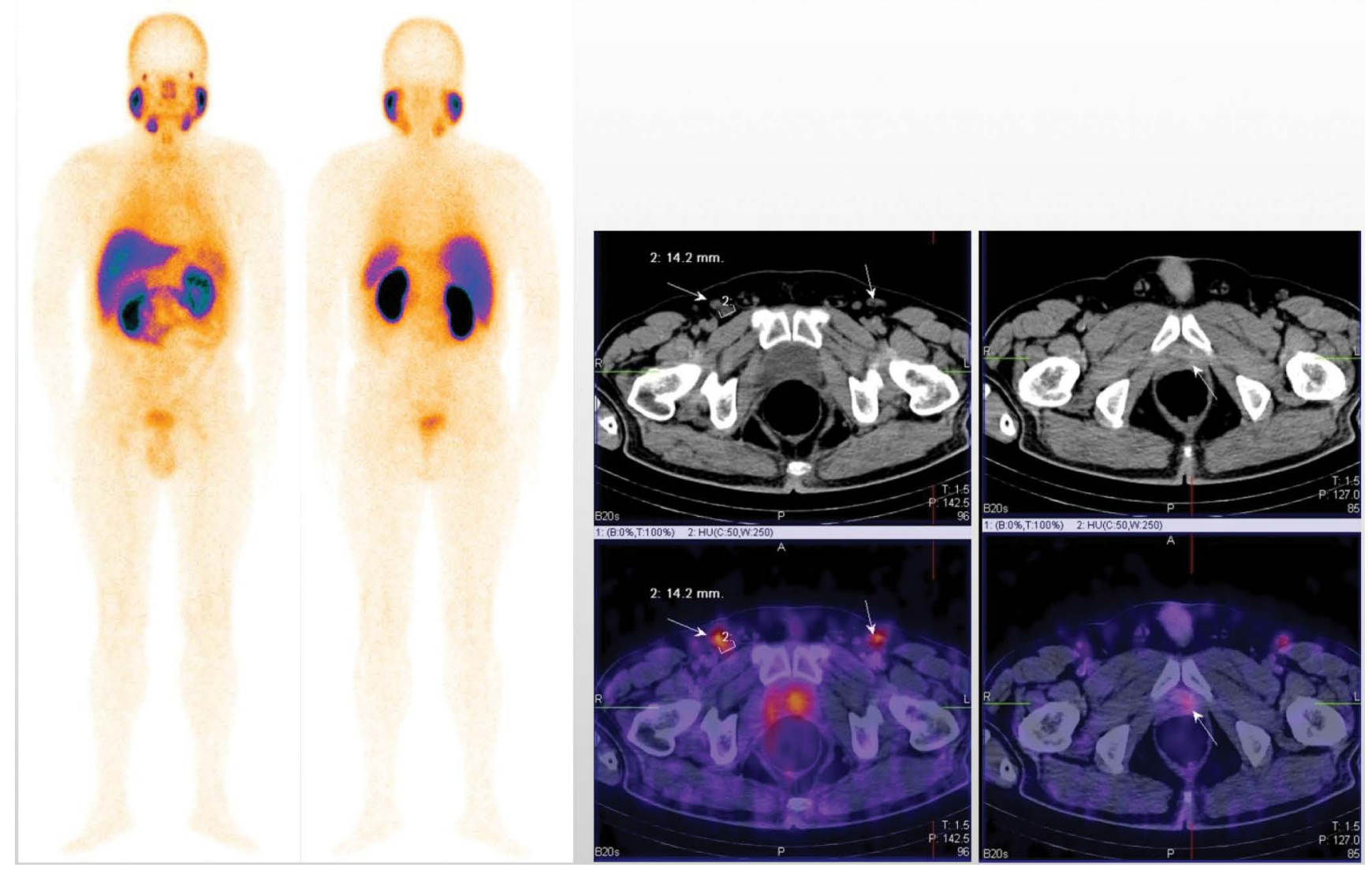

Figure 1. M/60yr with prostate cancer, pT2pNOMO, G2, Gl $=5(3+2)$. Radical prostatectomy (2018). PSA $=0.5 \mathrm{ng} / \mathrm{mL}$ (01/2019). Whole-body

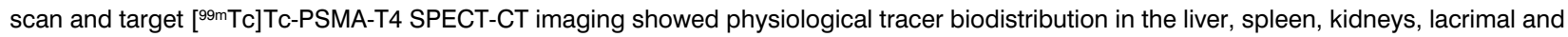
salivary glands, oral and nasal mucosa, bowels and urinary bladder. Intensive [ $\left.{ }^{99 \mathrm{~m} T \mathrm{~T}}\right]$ TC-PSMA-T4 uptake was visualized in the prostatic bed suspicious for local recurrence, follow-up was required. There was moderate symmetrical activity in the inguinal bilateral lymph nodes, which were visualized with normal structure and size, with well-depicted lymphocytic sinus, interpreted as reactive lymph nodes 


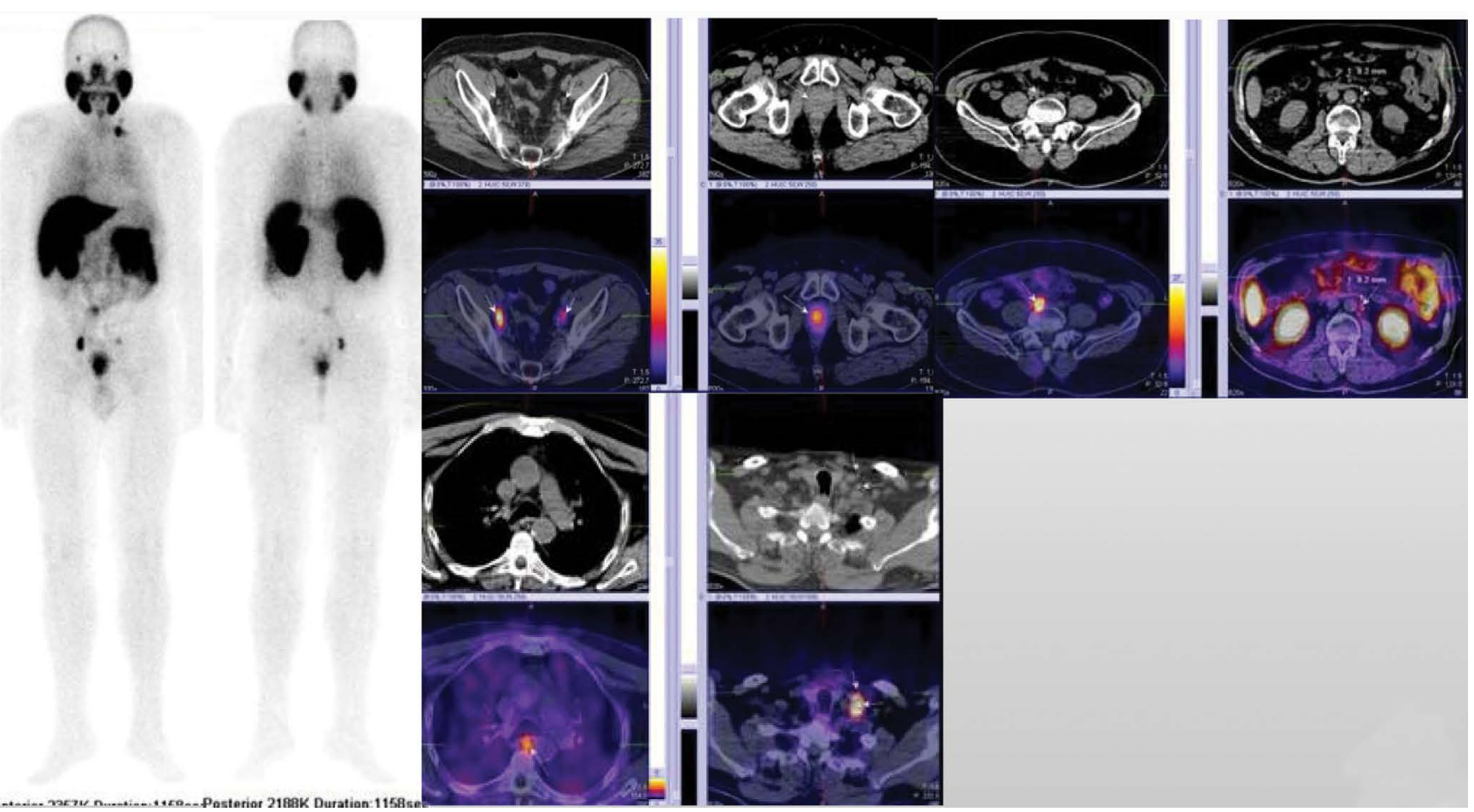

Figure 2. M/64yr with prostate cancer, pT3bpN1Mo, G3, GI = $9(5+4)$. Cytoreductive radiotherapy (01/2018), androgen deprivation therapy, chemotherapy. PSA = $2.157 \mathrm{ng} / \mathrm{mL}$ (01/2019). Whole-body scan and target [99mTc]Tc-PSMA-T4 SPECT-CT imaging showed local recurrence and enlarged bilateral obturator lymph nodes, common iliac lymph node on the right, periaortic with diameter $9.2 \mathrm{~mm}$ lymph node, paraesophageal retrotracheal lymph node and supraclavicular lymph node metastases with intensive tracer uptake
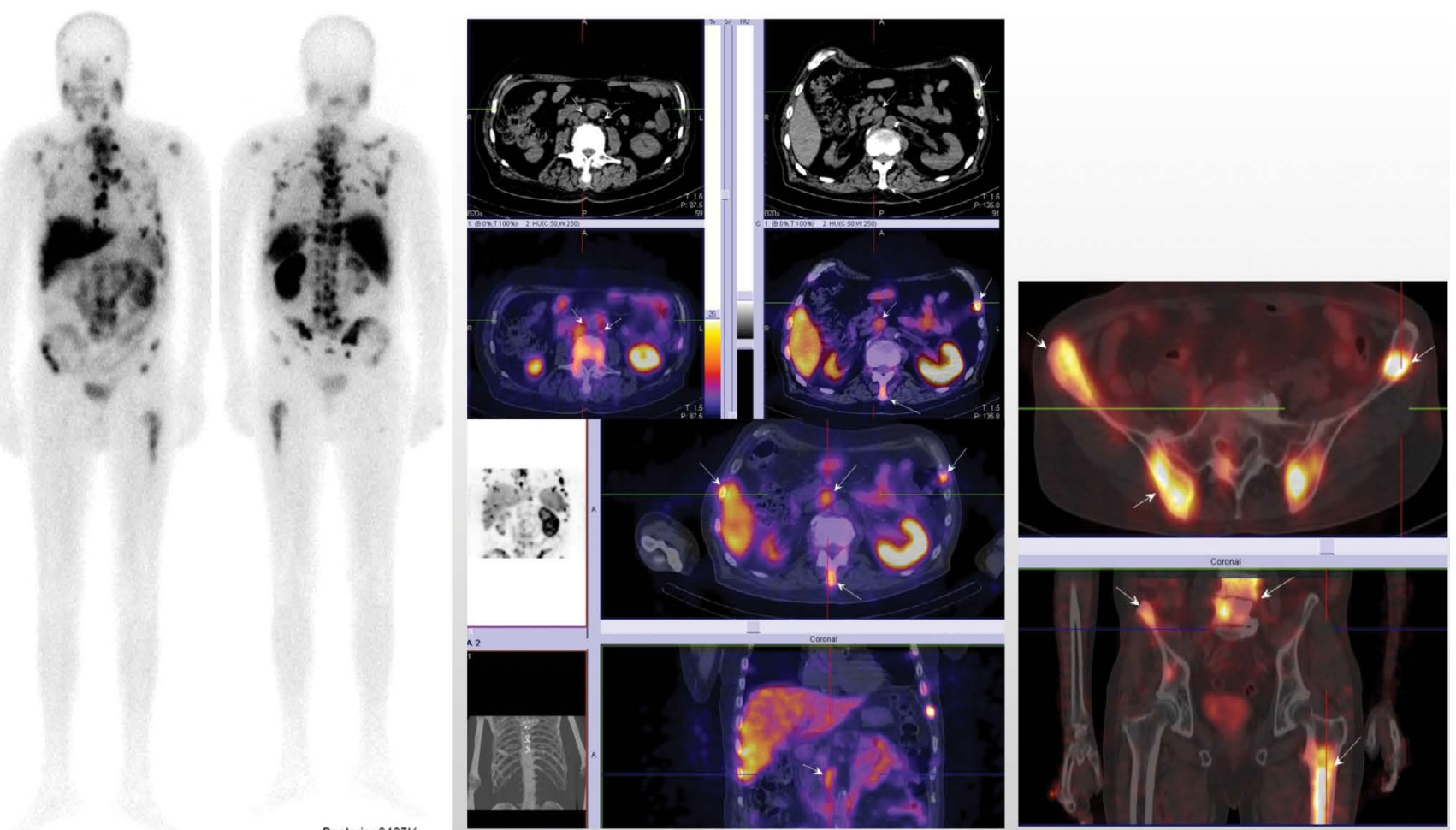

Figure 3. M/71yr with prostate cancer T3NOMO, G3, GI = $8(4+4)$. Radiotherapy definitive (09/2013). Androgen deprivation therapy. Chemotherapy and osteomodulators. PSA $=73 \mathrm{ng} / \mathrm{mL}$ (02/2019). Whole-body scan and target [99mTc]TC-PSMA-T4 SPECT-CT imaging showed multiple bone metastases and enlarged retroperitoneal lymph node metastases with intensive tracer uptake 

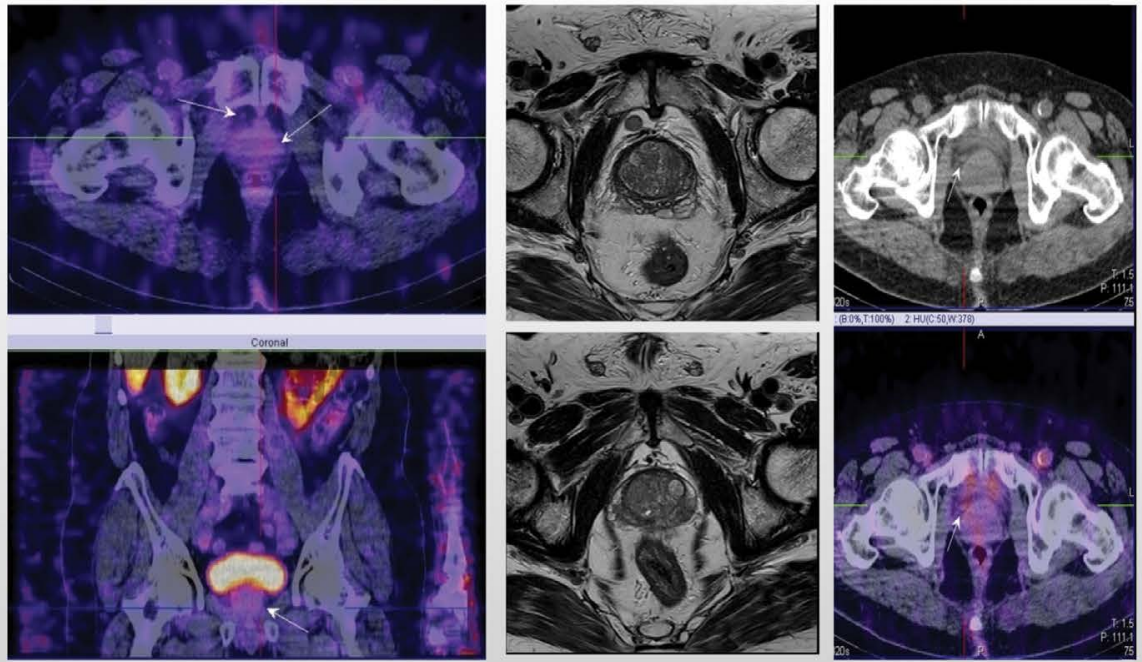

Figure 4. M/73yr with prostate cancer, $\mathrm{T} 4 \mathrm{~N} 1 \mathrm{MO}, \mathrm{G} 3, \mathrm{Gl}=9(4+5)$. Cytoreductive radiotherapy (03/2019) and androgen deprivation therapy. PSA $=0.30 \mathrm{ng} / \mathrm{mL}$ (06/2019). Whole-body scan and target [99mTc]Tc-PSMA-T4 SPECT-CT imaging showed enlarged prostatic gland and perivesical lymph nodes with intensive tracer uptake corresponding to MRT images. Disease persistence
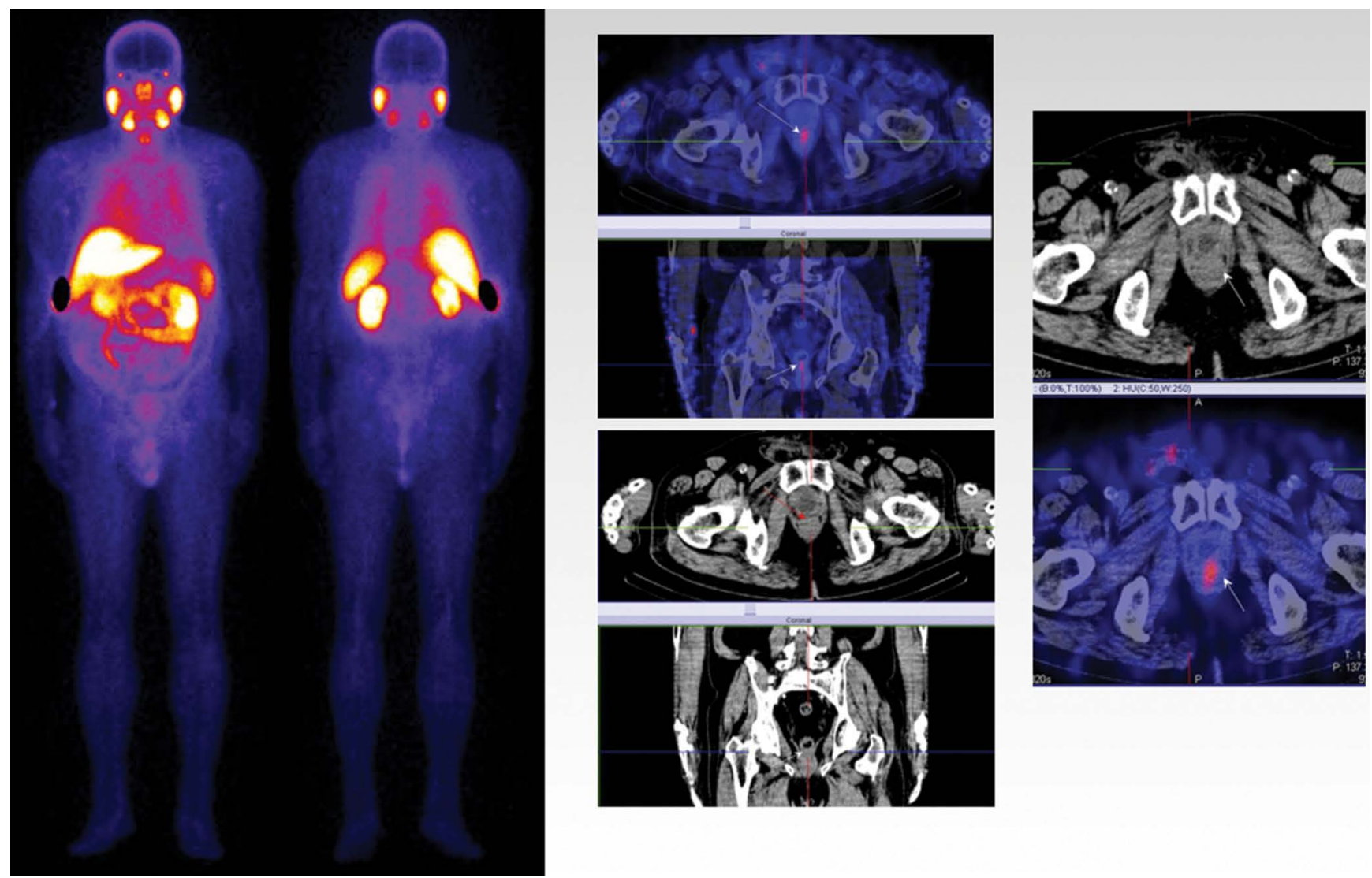

Figure 5. M/70yr with prostate cancer, pT2NOMO, G2, GI $=7(3+4)$. Radical prostatectomy (2017) and radiotherapy. PSA $=0.24 \mathrm{ng} / \mathrm{mL}(06 / 2019)$.

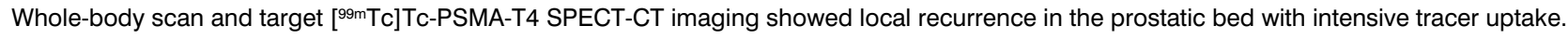
Disease progression 


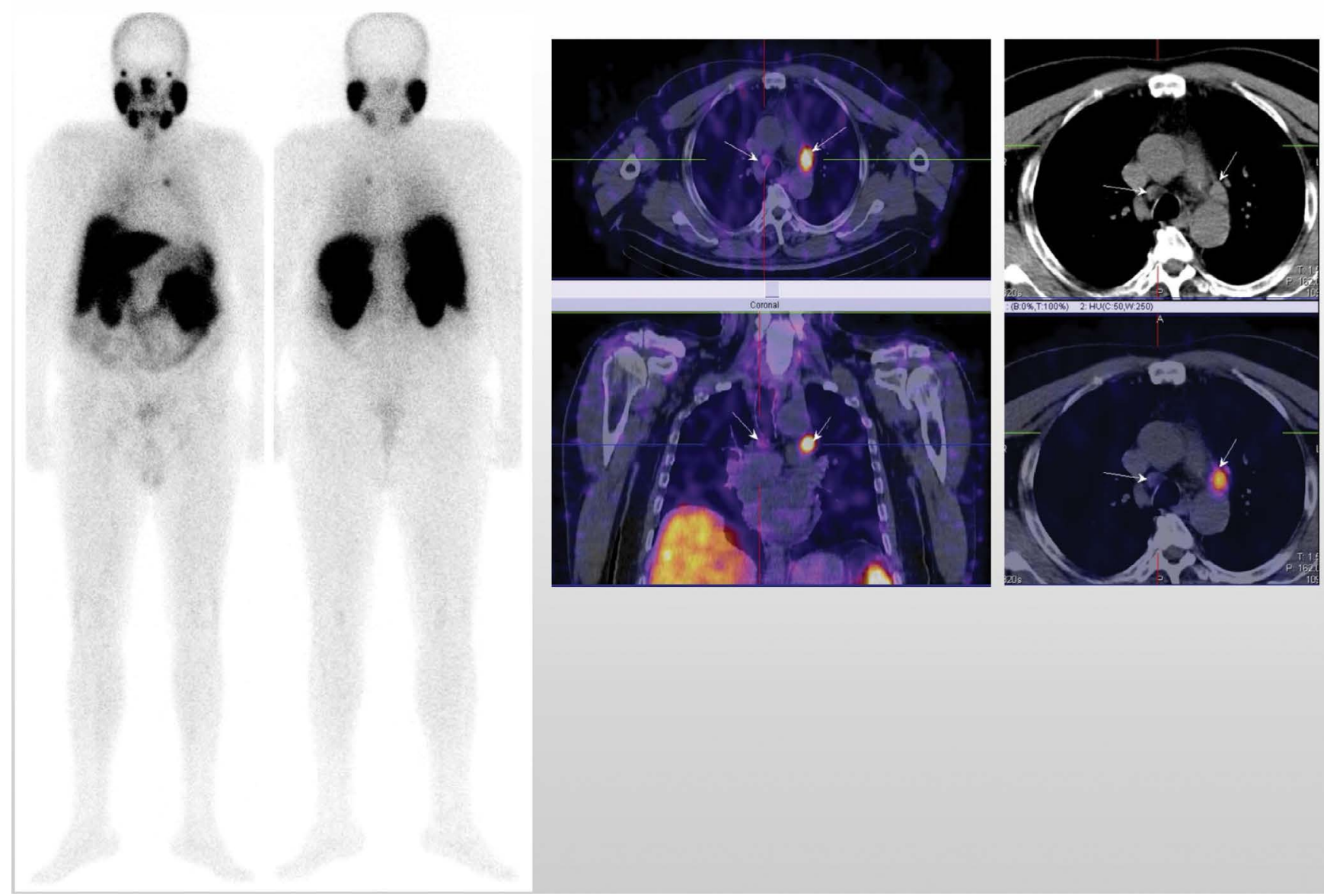

Figure 6. M/67yr with prostate cancer, pT3bpN1M0, GI = $7(4+3)$. Radical prostatectomy, radiotherapy (01/2018) and androgen deprivation therapy. PSA $=0.27 \mathrm{ng} / \mathrm{mL}$ (01/2019). Whole-body scan and target [ ${ }^{99 \mathrm{~m} T c]}$ Tc-PSMA-T4 SPECT-CT imaging showed enlarged mediastinal lymph node metastases with intensive tracer uptake

prostate bed and pelvic lymphadenopathy. SPECT-CT images were used for contouring the gross tumour volume (GTV) and the clinical tumour volume (CTV) in the radiotherapy planning (Fig. 9, 10).

Negative results were found in 5 patients. They were followed up after 6 months, and no pathological lesions with tracer uptake were visualized in the second study. In this group, a continuing increase in serum PSA was observed:

— in the first patient the value of PSA before the baseline [ ${ }^{99 \mathrm{~m} T c}$ ] TC-PSMA-T4 study was $0.12 \mathrm{ng} / \mathrm{mL}$ and 6 months later: $\mathrm{PSA}=1.42 \mathrm{ng} / \mathrm{mL}$;

- in the second patient, PSA levels were $0.23 \mathrm{ng} / \mathrm{mL}$ and $0.84 \mathrm{ng} / \mathrm{mL}$ respectively;

— in the third patient, PSA levels were $0.16 \mathrm{ng} / \mathrm{mL}$ and $0.25 \mathrm{ng} / \mathrm{mL}$ respectively;

— in the fourth patient, PSA levels were $0.50 \mathrm{ng} / \mathrm{mL}$ and $0.77 \mathrm{ng} / \mathrm{mL}$ respectively;

— in the fifth patient, PSA levels were $0.24 \mathrm{ng} / \mathrm{mL}$ and $0.47 \mathrm{ng} / \mathrm{mL}$ respectively.

Due to the continuing biochemical progression and negative scan of the [99mTc]Tc-PSMA-T4study, the results in these cases were interpreted as false-negative images. In all patients in this group, the baseline PSA was less than or equal to $0.50 \mathrm{ng} / \mathrm{mL}$.

Sensitivity of SPECT-CT study with [ ${ }^{99 m}$ Tc] Tc-PSMA-T4 for imaging of recurrent prostate cancer in 36 involved patients was $84.37 \%$ (27/32), specificity - 100\% (4/4) and accuracy - 86.11\% (31/36). For the clinical application of this study, the following could be summarized:

1. SPECT-CT imaging with [ ${ }^{99 \mathrm{~m} T \mathrm{~T}]}$ ] TC-PSMA-T4 could be applied in patients with prostate cancer and biochemical progression if PSA $\geq 0.50 \mathrm{ng} / \mathrm{mL}$ for the diagnosis of recurrent disease to determine personalized treatment for each patient.

2. To follow-up of patients after complex therapy for restaging of the disease in cases with unclear and uncertain findings from other imaging methods.

3. For imaging of local recurrence and/or metastases after therapy to perform target radiotherapy or SRT (salvage radiation therapy).

4. Specific uptake of this tracer, depicted by SPECT-CT images could have clinical importance of identifying and assessing PSMA expression before consideration of Radio Ligand Therapy (RLT) with [ $\left.{ }^{177} \mathrm{Lu}\right] \mathrm{Lu}-\mathrm{PSMA}$. 

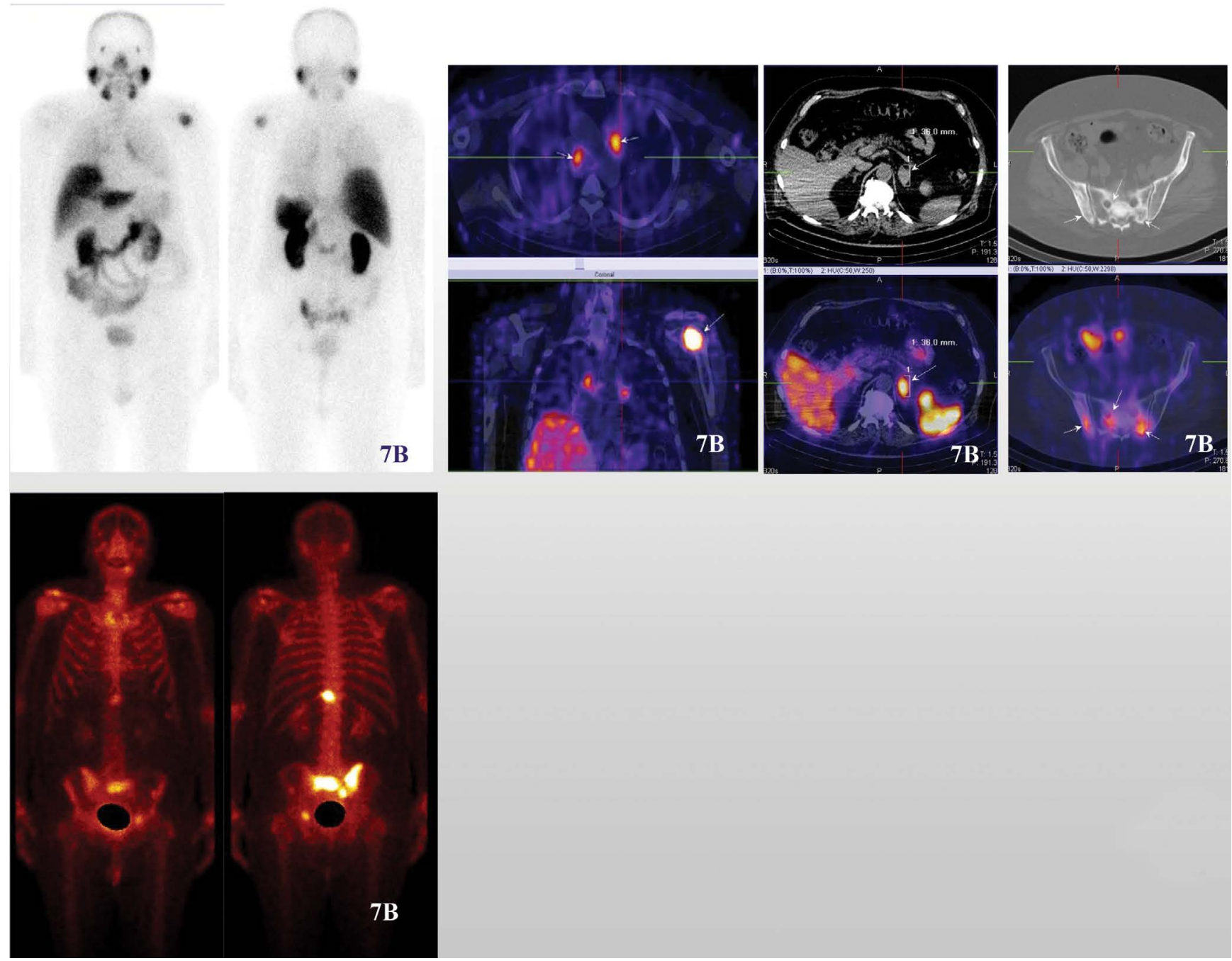

Figure 7A. M/79yr with prostate cancer, T3NOMO, G3, GI = 10 (35 + 5). Radiotherapy (2017), androgen deprivation therapy, chemotherapy. $\mathrm{PSA}=10.87 \mathrm{ng} / \mathrm{mL}$ (03/2019). Whole-body scan and target [ ${ }^{99 \mathrm{~m} T c}$ ]TC-PSMA-T4 SPECT-CT imaging showed multiple osteosclerotic bone lesions, partially negative due to prior treatment; B. Bone scan performed 6 months previously with a positive result for bone metastases in the pelvis, Th12 and left shoulder. New enlarged mediastinal lymph nodes and enlarged left adrenal gland, significant for metastases, were visualized. Disease progression

\section{Discussion}

The first results for clinical application of radiolabelled PSMA were published in 2013 [5] and this led to a qualitatively new nuclear medicine approach to this disease with the possibility of determining the optimal personalized therapy for patients [6, 10-12].

The cited sensitivity and specificity of the $\left[{ }^{68} \mathrm{Ga}\right] \mathrm{Ga}-\mathrm{PS}$ MA-11 studies are very high due to the better spatial resolution of the PET-CT camera [13]. Compared to them, the images obtained by SPECT camera are characterized by lower spatial resolution, which is significantly improved in the combined multimodal SPECT-CT devices with greatly increased quality of the obtained images [14].

The results received in the present prospective study of the

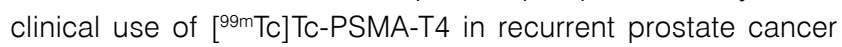
are comparable to those cited in the scientific literature $[13,15]$. In a large study of 225 patients reported by Schmidkonz et al. [15], it was found that the detection capabilities of prostate cancer with the biochemical progression of [99mTc]Tc-MIP-1404 SPECTCT are comparable to those of ${ }^{68} \mathrm{Ga}$-PSMA PET-CT at levels of $\mathrm{PSA}>2 \mathrm{ng} / \mathrm{mL}$. At lower than these values and a smaller volume of the tumour tissue substrate, the sensitivity of SPECT-CT studies is reduced to $54 \%$ [16]. Liu et al. [17], report that at lower PSA values $<0.5 \mathrm{ng} / \mathrm{mL}$ the diagnostic value of ${ }^{99 \mathrm{~m} T \mathrm{~T}}$ ] HYNIC-PSMA SPECT-CT is $48.6 \%$.

Another study showed that [ $\left.{ }^{99 m} \mathrm{TC}\right] \mathrm{PSMA}$ scanning was as sensitive as $\left[{ }^{68} \mathrm{Ga}\right] \mathrm{Ga}-\mathrm{PSMA}-11$ in 28 prostate cancer patients in terms of visualization of bone and lymphogenic metastatic foci, with PSA levels $>2 \mathrm{ng} / \mathrm{mL}$. SPECT-CT detection was lower when local recurrence was detected in the prostate bed in patients with evidence of biochemical progression with PSA $<0.5 \mathrm{ng} / \mathrm{mL}$ [15].

Goffin et al. [18], published data that the diagnostic value of SPECT-CT studies with [99mTC]TC-MIP-1404 correlated with the degree of differentiation of the primary tumour - Gleason score. In patients at intermediate risk and high-risk disease with $\mathrm{Gl} \geq 7$ $(3+4)$ detection rate reached $94 \%$ (86\% for MRT); for visualization 


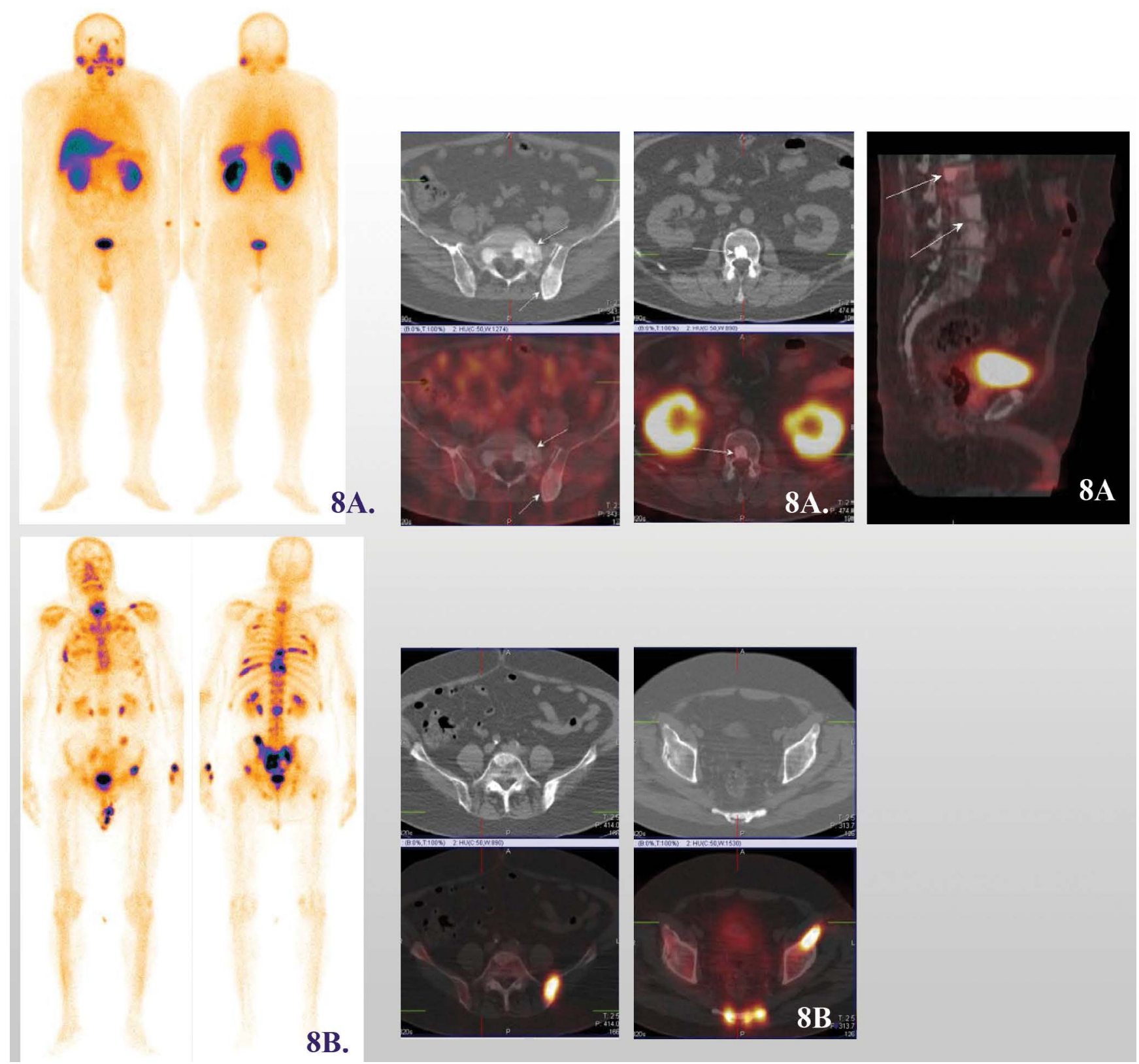

Figure 8A. M/62yr with prostate cancer, T3bN1M1, G3, GI = $10(35+5)$. Radiotherapy (2017), androgen deprivation therapy, osteomodulators. PSA $=0.66 \mathrm{ng} / \mathrm{mL}$ (07/2019). Whole-body scan and target [99mTc]TC-PSMA-T4 SPECT-CT imaging showed multiple osteosclerotic bone lesions, negative due to prior treatment; B. Bone scan was performed 6 months later due to increased PSA $=29 \mathrm{ng} / \mathrm{mL}$, with a positive result for active multiple bone metastases in the thoracic and lumbar vertebrae, bilateral ribs, pelvic bones and synchondrosis, left shoulder. There were no evidence of local recurrence, lymphogenic and visceral targets. The patient was planned for Xofigo therapy

of metastatic lymph nodes, the sensitivity and specificity were $90 \%$ and $67 \%$ respectively [18].

In patients with treated skeletal metastases and a negative [99m TC]TC-PSMA(I\&T) scan without lymphogenic and visceral secondary lesions, but with a progressive PSA elevation, control whole-body bone scintigraphy or follow-up by other standard visual methods is recommended. It would be appropriate to discuss the possibility of treatment with Xofigo in these patients [19].
Another clinical application of $\left.{ }^{99 \mathrm{~m}} \mathrm{Tc}\right] \mathrm{PSM}$ A SPECT-CT, which is not discussed in the present study but is cited in recently published scientific articles, is the introduction of this method for selective radio-guided surgery of metastatic lymph nodes and/or local recurrence in the bed of the prostate. Initial data are very encouraging for the future use of a gamma probe for intraoperative detection of metastatic foci in the pelvis, previously imaged by SPECT-CT using [99mTc]TC-PSMA(I\&T) and [99mTC]TC-PSMA-ALUG [20, 21]. 

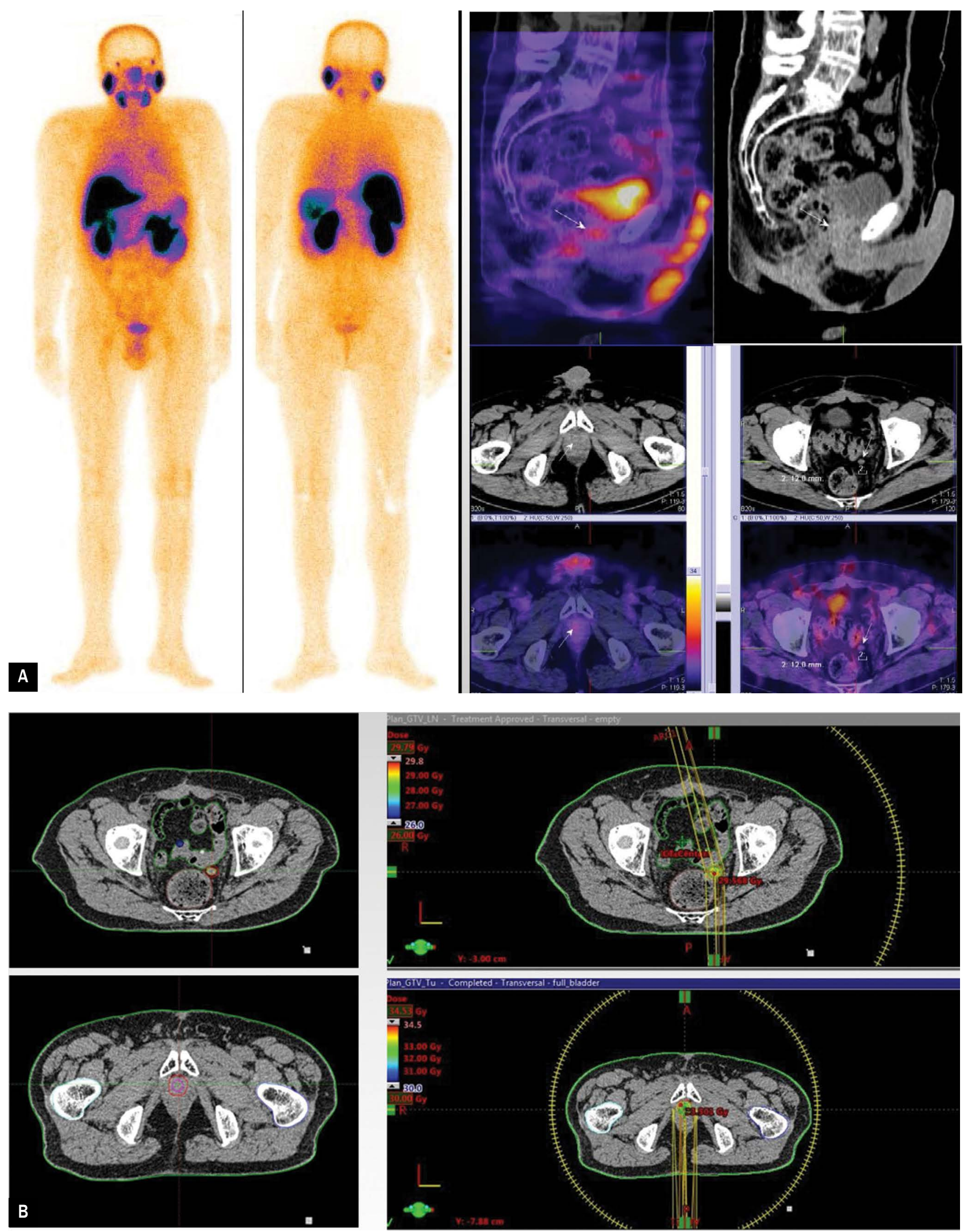

Figure 9A. M/75yr with prostate cancer, pT2cpNOMO, G2, GI = $7(4+3)$. Radical prostatectomy, radiotherapy (2015) and androgen deprivation therapy. PSA $=0.57 \mathrm{ng} / \mathrm{mL}$ (03/2019). Whole-body scan and target [99mTc]TC-PSMA-T4 SPECT-CT imaging showed local recurrence in the prostate bed and enlarged single perirectal lymph node on the left with intensive tracer uptake; B. Gross tumour volume (GTV) and Clinical Tumour Volume (CTV) delineation based on the ${ }^{99 \mathrm{~m} T \mathrm{~T}]}$ TC-PSMA-T4 imaging results in radiotherapy planning. Radiation dose distribution in the region of the local recurrence and the single enlarge perirectal lymph node on the left in the same patient 

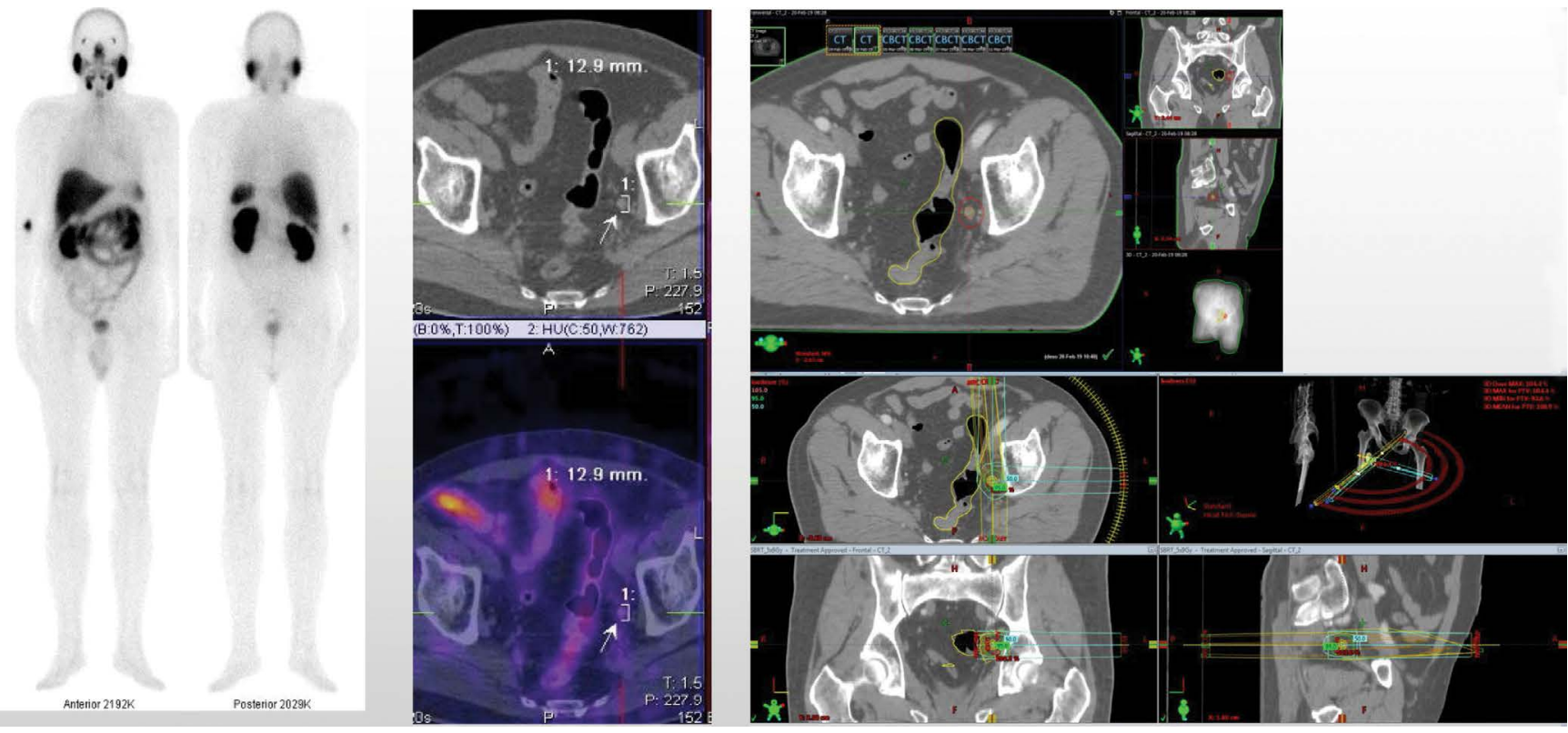

Figure 10. M/75yr with prostate cancer, pT2cpNOMO, Gl $=7(4+3)$ r. Radical prostatectomy $/ 2016 / \mathrm{PSA}=0.36 \mathrm{ng} / \mathrm{mL}$ (02.2019) Whole-body scan and target $\left[{ }^{99 \mathrm{~m} T C}\right]$ TC-PSMA-T4 SPECT-CT imaging showed enlarged single iliac lymph node on the left with intensive tracer uptake. Gross tumour volume (GTV) and Clinical Tumour Volume (CTV) delineation based on the [ ${ }^{99 \mathrm{mTC}}$ ]TC-PSMA-T4 imaging results in radiotherapy planning. Radiation dose distribution in the region of the single enlarged iliac lymph node on the left in the same patient. The PSA value decreased to $0.05 \mathrm{ng} / \mathrm{mL}$ (‥10.2019) after radiotherapy

\section{Conclusions}

Based on these results and the review of the published literature, it could be summarized that the new [99mTc]Tc-PSMA-T4 tracer was shown to have favourable biodistribution and kinetic behaviour. This radiopharmaceutical can be prepared in a short time, technically easy to perform radiolabelling and quality control, with a significantly lower radiation dose for the patient. A whole-body scan with subsequent SPECT-CT imaging is recommended within one to three hours after intravenous administration.

The use of [99mTc]Tc-PSMA-T4is a very good alternative as a diagnostic method in patients with prostate cancer in nuclear medicine centres that cannot produce $\left[{ }^{68} \mathrm{Ga}\right] \mathrm{Ga}-\mathrm{PSMA}$.

SPECT-CT study with [ $\left.{ }^{99 m} \mathrm{Tc}\right]$ TC-PSMA-T4 is a promising imaging tool showing high sensitivity and specificity with great diagnostic potential in patients with recurrent prostate cancer due to intensive target uptake in the local relapse of the prostate gland, lymphatic, bone and visceral metastases with a high diagnostic accuracy of 86.11\%. These parameters make [99mTc]TC-PSMA-T4 SPECT-CT studies an advanced visual method, cost-effective and widely applicable.

\section{Conflict of interest}

The authors report no conflicts of interest.

\section{References}

1. Ferlay $\mathrm{J}$, Colombet M, Soerjomataram I, et al. Cancer incidence and mortality patterns in Europe: Estimates for 40 countries and 25 major cancers in
2018. Eur J Cancer. 2018; 103: 356-387, doi: 10.1016/j.ejca.2018.07.005, indexed in Pubmed: 30100160.

2. European Cancer Information System-ECIS, European Commission 2018. https://ecis.jrc.ec.europa.eu/ (12.03.2019).

3. Kelloff GJ, Choyke P, Coffey DS, et al. Prostate Cancer Imaging Working Group. Challenges in clinical prostate cancer: role of imaging. AJR Am J Roentgenol. 2009; 192(6): 1455-1470, doi: 10.2214/AJR.09.2579, indexed in Pubmed: 19457806.

4. Engelbrecht MR, Jager GJ, Laheij RJ, et al. Local staging of prostate cancer using magnetic resonance imaging: a meta-analysis. Eur Radiol. 2002; 12(9): 2294-2302, doi: 10.1007/s00330-002-1389-z, indexed in Pubmed: 12195484.

5. Hillier SM, Maresca KP, Lu G, et al. 99mTc-labeled small-molecule inhibitors of prostate-specific membrane antigen for molecular imaging of prostate cancer. J Nucl Med. 2013; 54(8): 1369-1376, doi: 10.2967/jnumed.112.116624, indexed in Pubmed: 23733925.

6. von Eyben FE, Picchio M, von Eyben R, et al. Ga-Labeled Prostate-specific Membrane Antigen Ligand Positron Emission Tomography/Computed Tomography for Prostate Cancer: A Systematic Review and Meta-analysis. Eur Urol Focus. 2018; 4(5): 686-693, doi: 10.1016/j.euf.2016.11.002, indexed in Pubmed: 28753806.

7. Hupe MC, Philippi C, Roth D, et al. Expression of Prostate-Specific Membrane Antigen (PSMA) on Biopsies Is an Independent Risk Stratifier of Prostate Cancer Patients at Time of Initial Diagnosis. Front Oncol. 2018; 8: 623, doi: 10.3389/fonc.2018.00623, indexed in Pubmed: 30619757.

8. Oliveira JM, Gomes C, Faria DB, et al. Ga-prostate-specific Membrane Antigen Positron Emission Tomography/Computed Tomography for Prostate Cancer Imaging: A Narrative Literature Review. World J Nucl Med. 2017; 16(1): 3-7, doi: 10.4103/1450-1147.198237, indexed in Pubmed: 28217012.

9. Kratochwil C, Giesel FL, Stefanova M, et al. PSMA-Targeted Radionuclide Therapy of Metastatic Castration-Resistant Prostate Cancer with 177Lu-Labeled PSMA-617. J Nucl Med. 2016; 57(8): 1170-1176, doi: 10.2967/jnumed.115.171397, indexed in Pubmed: 26985056. 
10. Jones W, Griffiths K, Barata PC, et al. PSMA Theranostics: Review of the Current Status of PSMA-Targeted Imaging and Radioligand Therapy. Cancers (Basel). 2020; 12(6), doi: 10.3390/cancers12061367, indexed in Pubmed: 32466595.

11. Krimphove MJ, Theissen LH, Cole AP, et al. Performance and Impact of Prostate Specific Membrane Antigen-Based Diagnostics in the Management of Men with Biochemical Recurrence of Prostate Cancer and its Role in Salvage Lymph Node Dissection. World J Mens Health. 2020; 38(1): 32-47, doi: 10.5534/wjmh.180133, indexed in Pubmed: 30929322.

12. Schwarzenboeck SM, Rauscher I, Bluemel C, et al. PSMA Ligands for PET Imaging of Prostate Cancer. J Nucl Med. 2017; 58(10): 1545-1552, doi: 10.2967/jnumed.117.191031, indexed in Pubmed: 28687599.

13. Beheshti M, Manafi-Farid R, Geinitz H, et al. Multiphasic Ga-PSMA PET/CT in the Detection of Early Recurrence in Prostate Cancer Patients with a PSA Level of Less Than $1 \mathrm{ng} / \mathrm{mL}$ : A Prospective Study of 135 Patients. J Nucl Med. 2020; 61(10): 1484-1490, doi: 10.2967/jnumed.119.238071, indexed in Pubmed: 32060214.

14. Mariani G, Bruselli L, Kuwert $T$, et al. A review on the clinical uses of SPECT/CT. Eur J Nucl Med Mol Imaging. 2010; 37(10): 1959-1985, doi: 10.1007/s00259-010-1390-8, indexed in Pubmed: 20182712.

15. Schmidkonz C, Hollweg C, Beck M, et al. Tc-MIP-1404-SPECT/CT for the detection of PSMA-positive lesions in 225 patients with biochemical recurrence of prostate cancer. Prostate. 2018; 78(1): 54-63, doi: 10.1002/pros.23444, indexed in Pubmed: 29105797.
16. Liu C, Zhu Y, Su H, et al. Relationship between PSA kinetics and Tc-99m HYNIC PSMA SPECT/CT detection rates of biochemical recurrence in patients with prostate cancer after radical prostatectomy. Prostate. 2018; 78(16): 1215-1221, doi: 10.1002/pros.23696, indexed in Pubmed: 30027591.

17. Albalooshi B, Al Sharhan M, Bagheri F, et al. Direct comparison of TC-PSMA SPECT/CT and Ga-PSMA PET/CT in patients with prostate cancer. Asia Ocean J Nucl Med Biol. 2020; 8(1): 1-7, doi: 10.22038/aojnmb.2019.43943.1293, indexed in Pubmed: 32064277.

18. Goffin KE, Joniau S, Tenke P, et al. Phase 2 Study of Tc-Trofolastat SPECT/CT to Identify and Localize Prostate Cancer in Intermediate- and High-Risk Patients Undergoing Radical Prostatectomy and Extended Pelvic LN Dissection. J Nucl Med. 2017; 58(9): 1408-1413, doi: 10.2967/jnumed.116.187807, indexed in Pubmed: 28302763.

19. Trabulsi EJ, Rumble RB, Jadvar H, et al. Optimum Imaging Strategies for Advanced Prostate Cancer: ASCO Guideline. J Clin Oncol. 2020; 38(17): 1963-1996, doi: 10.1200/JCO.19.02757, indexed in Pubmed: 31940221.

20. Maurer T, Robu S, Schottelius M, et al. Technetium-based Prostate-specific Membrane Antigen-radioguided Surgery in Recurrent Prostate Cancer. Eur Urol. 2019; 75(4): 659-666, doi: 10.1016/j.eururo.2018.03.013, indexed in Pubmed: 29625755.

21. Su HC, Zhu Y, Hu SL, et al. The Value of Tc-PSMA SPECT/CT-Guided Surgery for Identifying and Locating Lymph Node Metastasis in Prostate Cancer Patients. Ann Surg Oncol. 2019; 26(2): 653-659, doi: 10.1245/s10434-0186805-y, indexed in Pubmed: 30324468. 